\title{
CUENTAS Y TEMBETÁS MALACOLÓGICOS DE LOS GRUPOS CAZADORES- RECOLECTORES PREHISPÁNICOS DEL HUMEDAL DEL PARANÁ INFERIOR
}

\section{SHELL BEADS AND TEMBETÁS FROM PREHISPANIC HUNTER-GATHERERS OF LOW PARANÁ WETLAND}

\author{
Natacha Buc ${ }^{1}$, Alejandro Acosta ${ }^{2}$ y Daniel Loponte ${ }^{3}$ \\ ${ }^{1}$ CONICET - Instituto Nacional de Antropología y Pensamiento Latinoamericano. 3 \\ de Febrero 1378, C1426 CABA. natachabuc@gmail.com \\ 2 CONICET - Instituto Nacional de Antropología y Pensamiento Latinoamericano. \\ 3 de Febrero 1378, C1426 CABA acostaalejandroalberto@gmail.com \\ ${ }^{3}$ CONICET - Instituto Nacional de Antropología y Pensamiento Latinoamericano. 3 \\ de Febrero 1378, C1426 CABA dashtown@gmail.com
}

Presentado: 10/11/2018 - Aceptado: 27/03/2019

\begin{abstract}
Resumen
Entre los grupos cazadores-recolectores que ocuparon el humedal del río Paraná inferior durante el Holoceno tardio, el conjunto más numeroso de adornos es el de las cuentas y tembetás hechos sobre valvas de moluscos. En trabajos previos observamos que estos elementos presentan similitudes morfológicas a nivel intersitio, con pequeñas variaciones formales. En este trabajo evaluamos la posibilidad de que estos elementos hayan funcionado como demarcadores sociales. En este sentido esperamos un patrón homogéneo tanto en la forma general y sus atributos, como en el tamaño. Para ello analizamos métrica y morfológicamente los conjuntos malacológicos provenientes de diez sitios arqueológicos del área. Los resultados muestran tendencias diferentes para las cuentas y los tembetás. Las primeras se distribuyen de manera homogénea en el espacio con un patrón morfológico y métrico compartido que sólo excluye uno de los sitios arqueológicos. Los tembetás, por su parte, son menos frecuentes y presentan dos variantes morfométricas que pueden responder a variaciones individuales o reflejar parcialidades étnicas.
\end{abstract}

Palabras clave: Paraná inferior, cuentas, tembetás, valvas

\begin{abstract}
Among hunter-gatherer groups that inhabited the low Parana wetland during Late Holocene, the most numerous assemblages of ornaments are composed by shell beads and tembetás. In previous works we observed that the assemblages show inter-site morphological similarities with little formal variations. In this paper we test the idea that these elements were used as social markers. Consequently, we expect an homogeneous pattern in the general form and the form of their attributes, as well as the metrical values. For this purpose, we analyse metrical and morphological data of shell assemblages from ten archaeological sites of the study area. Results show different tendencies for shell beads and tembetás. Shell beads are homogenously distributed in the region with a shared morphologic and metric pattern that only excludes one of the
\end{abstract}


archaeological sites. Tembetás are less frequent and show two morpho-metric variants that could be a response either to individual variability or to ethnic identification.

Key words: Paraná inferior, beads, tembetás, shell

\section{Introducción}

Los grupos cazadores-recolectores que ocuparon el humedal del río Paraná inferior durante el Holoceno tardío utilizaron distintas materias primas para la elaboración de adornos (Acosta et al. 2015). El conjunto más numeroso está compuesto por cuentas y tembetás (elementos en T que se colocan en la barbilla) hechos sobre valvas de moluscos, en su mayoría fluviales, aunque ocasionalmente se registra la utilización de especies terrestres locales y marinas (Acosta et al. 2015a, 2017). Los conjuntos arqueológicos del área presentan rasgos materiales homogéneos a lo largo del espacio, especialmente en su tecnología (Buc 2012, Silvestre 2016, Pérez 2015). Sin embargo, cierta variabilidad también fue registrada en rasgos particulares, algunos de ellos considerados estilísticos (Alí 2016, Buc 2012, Silvestre 2017). En una publicación anterior analizamos los conjuntos de adornos en donde incluimos pendientes hechos en caninos, arcilla e incluso cuentas líticas, además de las cuentas y tembetás en valva (ver Acosta et al. 2015a). Allí concluimos que los conjuntos presentan similitudes morfológicas generales a lo largo del espacio analizado, aunque también registramos pequeñas variaciones definidas, en principio, en función de la forma artefactual. En aquella oportunidad propusimos que estos elementos podrían haber funcionado como demarcadores sociales, tratándose posiblemente de un código simbólico compartido entre los diferentes grupos, siendo la heterogeneidad registrada producto de la variación en su producción artesanal.

Creer que los objetos ornamentales fueron o son fundamentalmente utilizados con fines meramente decorativos o estéticos constituye una sobresimplificación ( $c f$. Vibe 2007). En las últimas décadas, los estudios relacionados con su manufactura y uso han cobrado una gran importancia para abordar distintos problemas vinculados con el origen y evolución del lenguaje, el simbolismo, las capacidades cognitivas y el incremento de la complejidad en la organización social de los seres humanos anatómicamente modernos (Kuhn y Stiner 2007a, Moro Abadía y Nowell 2015, Sterelny y Hiscock 2014, Zilhão 2007), aunque una parte de estas conductas también habría alcanzado a los neandertales (para una síntesis actual de esta problemática ver Barciela González 2017).

Los adornos personales han sido utilizados de distintas maneras y para diferentes propósitos, siendo muy diversos los significados o funciones que pudieron haber adquirido a través del tiempo (ver ejemplos en Ember y Ember 2011, Vanhaeren 2005). En este trabajo consideramos que el estilo artefactual es un medio para el intercambio de información (Roach y Eicher 1979, Wobst 1976, Wiessner 1984). La información transmitida puede reflejar el status social, la identidad o pertenencia étnica, así como aspectos religiosos o emblemáticos de sus usuarios, entre otras cosas (Kuhn et al. 2001; Kuhn y Stiner 2007a y b, Roach y Eicher 1979, Trubbit 2003, White 1993, 2007). De este modo, la elaboración de ornamentos corporales puede ser analizada como una variante 
tecnológica que posibilita comunicar información de diversa índole (sensu Kuhn y Stiner 2007a, Stiner 2014). Desde una perspectiva similar se ha propuesto que los ornamentos pueden ser analizados a través de la teoría de la señalización costosa (Bliege Bird y Smith 2005, Kuhn 2014, Rorabaugh y Shantry 2016).

En Argentina, desde principios del siglo XX se han realizado menciones y/o estudios relacionados con la utilización de la malacofauna para elaboración de objetos ornamentales (e.g. Boman 1920, Doello Jurado 1940, Martínez Soler 1958-59, Outes 1917). En las últimas décadas, y en diferentes regiones del país se han efectuado numerosas contribuciones al respecto (Cimino y Pastorino 2007, Gordillo y Fabra 2014, Flensborg 2017, Leonardt 2013, 2014, 2017, Oliva y Lisboa 2006, Pastor et al. 2017, Zubimendi 2010).

\section{Contextualización del problema}

Los sitios arqueológicos bajo estudio están localizados en dos unidades ecológicas diferentes del humedal que forma el río Paraná en su tramo inferior: las planicies inundables de Entre Ríos, al norte, y los Bajíos Ribereños, al sur (Figura 1). Se trata en todos los casos de depósitos generados por grupos cazadores recolectores durante el tramo final del Holoceno tardío. La mayoría se concentra entre los 900 y 1100 años ${ }^{14} \mathrm{C}$ $\mathrm{AP}$, distanciándose de esa distribución en el extremo más temprano, Cerro Mayor con $\sim 1600$ años ${ }^{14} \mathrm{C}$ AP y, en el más tardío, La Bellaca II con 700 años ${ }^{14} \mathrm{C}$ AP (Tabla 1).

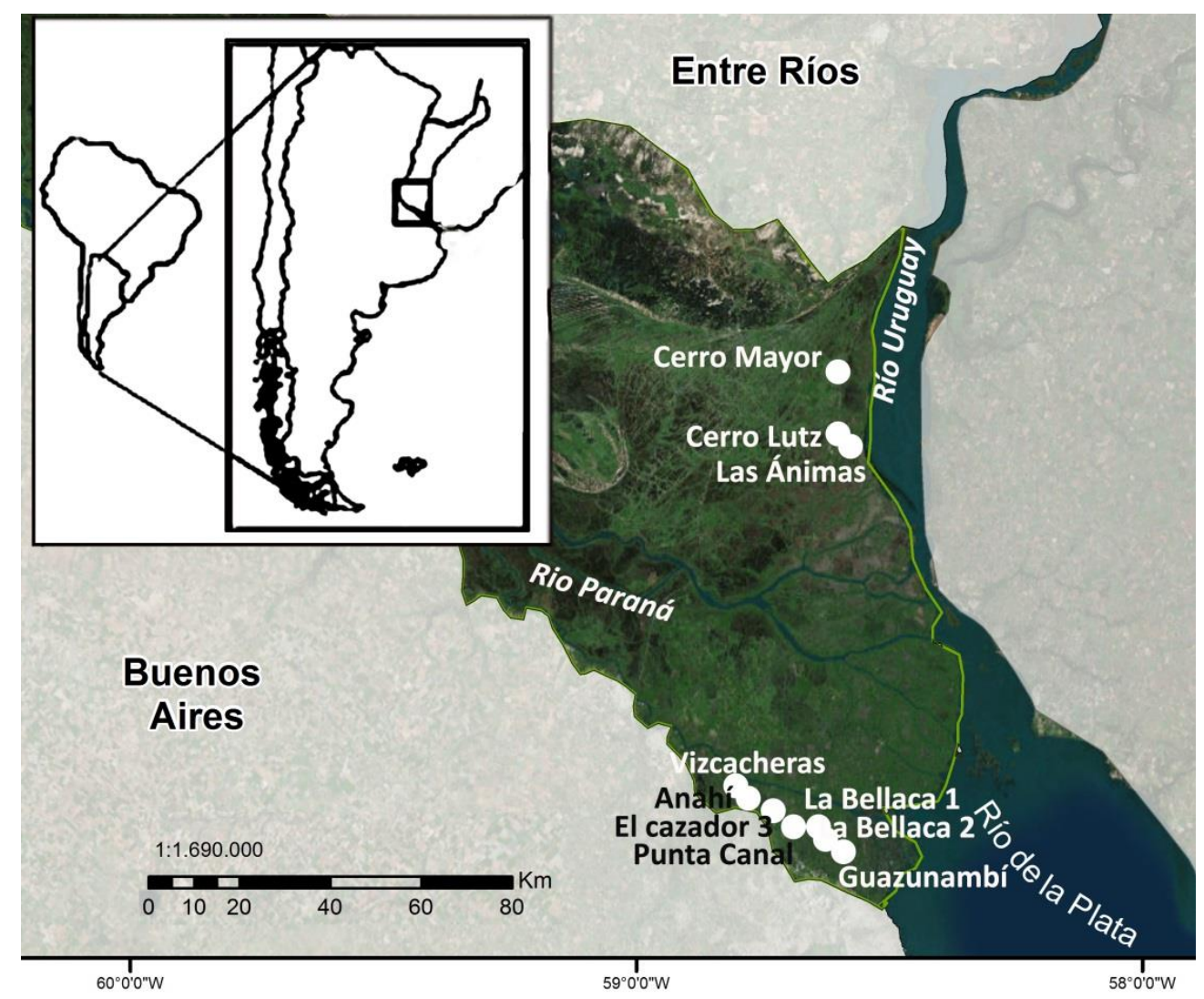

Figura 1. Sitios analizados en el trabajo. 
Los sitios arqueológicos de los Bajíos Ribereños están compuestos por una o varias ocupaciones penecontemporáneas realizadas sobre albardones, geoformas que constituyen los puntos más elevados del paisaje (Loponte 2008, Acosta et al. 2010). Las ocupaciones, cuya potencia arqueológica varía entre 40 y $90 \mathrm{~cm}$, son producto de eventos temporalmente acotados y corresponden a una misma unidad arqueológica ya que no se observan diferencias cronoestratigráficas ni culturales intradepósito (Loponte 2008, ver también Loponte et al. en este volumen). Todos estos sitios han sido considerados como loci de actividades múltiples o bases residenciales. En ellos se recuperaron restos que evidencian desde la manufactura, reparación y uso de artefactos cerámicos, líticos, óseos y malacológicos, hasta el procesamiento y consumo de diferentes tipos de recursos, y actividades funerarias (Torres 1911, Mazza y Loponte 2012).

En las planicies de Entre Ríos los sitios arqueológicos discutidos en ese trabajo responden a procesos de formación diferentes. El sitio Cerro Mayor fue elevado artificialmente sobre un cordón litoral alcanzando una potencia de $2.60 \mathrm{~m}$ (Loponte et al. 2016). Una o varias ocupaciones humanas están representadas de manera penecontemporánea con edades que se ubican entre los 1561 y 1600 años ${ }^{14} \mathrm{C}$ AP (Tabla 1). Los sitios Las Ánimas y Cerro Lutz se ubican a unos pocos kilómetros de distancia. Están formados sobre albardones y presentan características similares en su composición. Se trata, en ambos casos, de bases residenciales en donde también se efectuaron actividades mortuorias, habiéndose registrado una elevada y diversa cantidad de inhumaciones humanas (Acosta y Mazza 2016; Acosta et al. 2010; Mazza et al. 2018). En Las Ánimas, un fechado realizado sobre huesos humanos arrojó una antigüedad de $1121 \pm 31$ años ${ }^{14} \mathrm{C}$ AP. En cuanto a Cerro Lutz, las dataciones efectuadas se ubican dentro de un rango temporal que se extiende entre los 1100 y 700 años ${ }^{14} \mathrm{C}$ AP (ver Tabla 1).

En este último sitio se han registrado lentes con una alta y concentrada cantidad de valvas, fundamentalmente de Diplodon sp., conformando verdaderos concheros (Acosta et al. 2010). En los otros depósitos las valvas se presentan generalmente desarticuladas, distribuidas de manera dispersa o formando pequeñas concentraciones asociadas al resto de los materiales arqueológicos (para más detalles ver Loponte et al. en este volumen). Todos los sitios fueron generados por grupos humanos cuya subsistencia estuvo basada principalmente en la pesca, complementada con la explotación de cérvidos (Blastocerus dichotomus y Ozotoceros bezoarticus) y roedores (Myocastor coypus y Cavia aperea), además de la recolección y consumo de distintos recursos vegetales, incluyendo probablemente algunos productos domesticados que se habrían cultivado en pequeños huertos (Acosta 2005; Loponte 2008).

Los diferentes depósitos comparten además una serie de propiedades tecnológicas. En primer lugar, el rol central que tuvo la alfarería y la complementariedad con las tecnologías líticas y óseas. Si bien en el trabajo de todas las materias primas notamos la existencia de conceptos tecnológicos generales compartidos, principalmente a partir de la homogeneidad en las formas artefactuales y las técnicas de manufactura, también se ha detectado cierta 
variabilidad. El caso de la alfarería es el más evidente porque las diferencias radican en la decoración cerámica: hay conjuntos donde los tiestos decorados presentan un alto porcentaje, mientras que en otros la cerámica es predominantemente lisa (Loponte 2008). Entre los casos analizados, en los sitios Anahí y Punta Canal la alfarería presenta un mismo patrón de motivos (Alí 2016), mientras que, en los restantes, los fragmentos cerámicos son mayoritariamente lisos. La tecnología lítica muestra una tendencia de baja representación general en el área con características estilísticas homogéneas donde dominan las lascas de filo natural y un mismo diseño de puntas de proyectil (Silvestre 2017). Sin embargo, existen patrones que permiten diferenciar internamente los conjuntos de los Bajíos Ribereños siguiendo la clasificación de la alfarería mencionada, y a su vez, a estos, de los de las planicies de Entre Ríos. En primer lugar, los artefactos líticos son más abundantes en los sitios con cerámica decorada, pero a su vez, los conjuntos meridionales tienen menor cantidad de artefactos que los de Entre Ríos. Además, los sitios de Bajíos Ribereños presentan una mayor variabilidad en la explotación de materias primas. Si bien la caliza silicificada predomina en ambos sectores, la cuarcita está más representada en los Bajíos Ribereños (Silvestre 2017). En la tecnología ósea hasta el momento sólo se ha registrado la existencia de variabilidad en los rasgos estilísticos de un único grupo morfofuncional, que es el de los arpones. Una variante fue registrada al norte del Paraná guazú (sitio Cerro Lutz en las planicies de Entre Ríos, en este caso), mientras que la otra está ampliamente difundida al sur de este río (todos los sitios de los Bajíos Ribereños discutidos en este trabajo, Buc 2012). Por lo demás, lo sitios arqueológicos comparten nociones generales en la tecnología ósea con representación de grupos morfológicos y selección de materia prima (Buc 2012).

Los diferentes conjuntos arqueológicos también comparten un código simbólico expresado a través de la presencia de tres tipos de adornos principales: pendientes hechos sobre caninos de carnívoros (Acosta et al. 2015b), cuentas y tembetás sobre valva (Acosta et al. 2015a). En Acosta et al. 2015b analizamos la variabilidad presente en los pendientes hechos sobre caninos de diferentes carnívoros. Notamos que el conjunto es altamente homogéneo en el espacio considerado. Si bien existe variabilidad en las especies seleccionadas para la manufactura de los pendientes, esta no presenta un patrón direccional sino que, por el contrario, es producto de la tasa de encuentro de los diferentes taxones en busca de una misma forma común (Acosta et al. 2015b). En Acosta et al. 2015a analizamos las cuentas y tembetás hechos en valva, concluyendo estos serían elementos de bajo costo de producción ya que están realizados sobre materiales disponibles localmente. Su potencial replicación a nivel regional permite pensar que estos elementos funcionaron como demarcadores étnicos a lo largo del área.

En este trabajo proponemos que este comportamiento implicó una selección en la forma y tamaño de las cuentas y tembetás en la cuenca del Paraná inferior durante el Holoceno tardío. La variación observada entre los conjuntos es consecuencia de la producción artesanal y no de la invención en contextos socialmente independientes. Esperamos, por lo tanto, encontrar un modelo común en las estructuras morfológicas y métricas de los diferentes conjuntos independientemente del rango cronológico o espacial considerado. La variación se 
notará en los rasgos de producción de los artefactos, que, en el caso de las cuentas, se calibrará a partir del tipo y tamaño de perforación. Como hipótesis secundaria se plantea que la producción de los conjuntos ornamentales de valvas es local. Además de la selección de materia prima disponible localmente, esperamos encontrar elementos que demuestren las diferentes etapas de manufactura tanto de las cuentas como de los tembetás. Asimismo, esperamos registrar rasgos morfológicos y métricos estandarizados al interior de cada conjunto arqueológico.

\begin{tabular}{|c|c|c|c|c|c|}
\hline Sitio & Edad ${ }^{14} \mathrm{C}$ & Fechado Calibrado & Taxa & Lab. & Referencia \\
\hline Anahí (A) & $1020 \pm 70$ & $1017-1151(p=1)$ & Myocastor coypus & Beta 147108 & Loponte (2008) \\
\hline \multirow{6}{*}{ Cerro Lutz (CL) } & $730 \pm 70$ & $1219-1402(p=1)$ & Homo sapiens & LP-1711 & \multirow{6}{*}{ Buc y Loponte (2016) } \\
\hline & $795 \pm 42$ & $1228-1256$ AD $(p=1)$ & H. sapiens & AA77311 & \\
\hline & $916 \pm 42$ & 1043-1231 AD $(\mathrm{p}=0,97)$ & Canis familiaris & AA77312 & \\
\hline & $953 \pm 47$ & $1030-1214(\mathrm{p}=1)$ & Syagrus romanzoffiana & AA103648 & \\
\hline & $976 \pm 42$ & 1024-1192 AD (p=0,99) & H. sapiens & AA77310 & \\
\hline & $1116 \pm 45$ & $880-1042$ AD $(p=1)$ & H. sapiens & AA103643 & \\
\hline \multirow{5}{*}{ Cerro Mayor $(\mathrm{CM})$} & $1561 \pm 45$ & $516-610 \mathrm{AD}(\mathrm{p}=0,81)$ & Blastocerus dichotomus & AA97469 & \multirow{5}{*}{ Loponte et al. (2016) } \\
\hline & $1574 \pm 45$ & $472-589$ AD $(p=1)$ & B. dichotomus & AA97457 & \\
\hline & $1594 \pm 59$ & 435-552 AD $(p=0,89)$ & C. familiaris & AA103658 & \\
\hline & $1600 \pm 33$ & $460-542 \mathrm{AD}(\mathrm{p}=0,85)$ & M. coypus & AA97466 & \\
\hline & $1665 \pm 45$ & $381-482 \mathrm{AD}(\mathrm{p}=0,88)$ & H.sapiens & AA97468 & \\
\hline \multirow{4}{*}{ El Cazador 3 (EC3) } & $921 \pm 43$ & $1038-1229$ AD $(p=0,98)$ & B. dichotomus & AA97470 & \multirow{4}{*}{ Buc y Loponte (2016) } \\
\hline & $1031 \pm 36$ & 1084-1138 AD $(p=0,59)$ & H.sapiens & AA97464 & \\
\hline & $1063 \pm 46$ & 966-1150 AD $(\mathrm{p}=0,95)$ & Lama guanicoe & AA103657 & \\
\hline & $1091 \pm 43$ & 981-1046 AD $(\mathrm{p}=0,93)$ & L. guanicoe & AA103656 & \\
\hline Guazunambí (Gz) & $940 \pm 60$ & 1024-1231 AD $(\mathrm{p}=0,97)$ & B. dichotomus & Beta 147109 & Loponte (2008) \\
\hline La Bellaca I & $1100 \pm 70$ & 1023-1271 AD $(\mathrm{p}=1)$ & Mammalia & LP-1288 & Loponte (2008) \\
\hline La Bellaca II (LBII) & $680 \pm 80$ & 1395-1595 AD $(\mathrm{p}=0,98)$ & B. dichotomus & LP-1263 & Loponte (2008) \\
\hline \multirow{2}{*}{ Las Vizcacheras (LV) } & $1090 \pm 40$ & $970-1029$ AD $(p=0,97)$ & L. guanicoe & Beta 148237 & Loponte (2008) \\
\hline & $1070 \pm 60$ & 946-1159 AD $(p=0,87)$ & S. romanzoffiana & LP-1401 & Loponte (2008) \\
\hline Punta Canal (PC) & $900 \pm 80$ & $1026-1283$ AD $(p=1)$ & B. dichotomus & LP-1293 & Arrizurieta et al. (2010) \\
\hline
\end{tabular}

Tabla 1. Fechados de los sitios analizados en el trabajo. Calib Rev 7.0.4 SHCal

Para someter a prueba estas ideas se analizan las propiedades del conjunto de adornos malacológicos proveniente de 9 sitios arqueológicos (ver Figura 1; Tabla 1). En esta oportunidad evaluamos la distribución espacio-temporal de los objetos mencionados, sus propiedades métricas, morfológicas, y los rasgos macro y microscópicos de las perforaciones. Se evalúa, además, el origen de un conjunto de fragmentos de valvas que podrían estar vinculadas a su producción. Sobre la base de los resultados obtenidos discutimos el posible rol o función de los mismos en el contexto antes mencionado.

\section{Materiales y métodos}

Las cuentas se clasifican de acuerdo a su morfología en automorfas (conservan la forma biológica) o xenomorfas (forma artificial) (Suárez Diez 2002) y, a su vez, según su contorno en: circulares/sub-circulares, subcuadrangulares, ovales o irregulares (Leonardt 2016). Se definieron como "anillos" aquellas cuentas circulares cuyo largo y ancho son iguales o casi iguales (diferencia $<0,5 \mathrm{~mm}$ ). A 
continuación, se considera la estructura métrica de las cuentas, tomando el espesor máximo en todos los casos, diámetro máximo en las cuentas circulares y subcirculares, y largo y ancho máximos en las subcuadrangulares e irregulares (Leonardt 2017). De la perforación se ponderó el tamaño, la localización (centrada, levemente desplazada o completamente desplazada), tipo (bicónica, cónica o indeterminada) y la cara de inicio (interna, interna, indeterminada; Leonardt 2017). Para registrar estas últimas variables se utilizó lupa binocular a 20X. Además, se consideró la porción de valva utilizada como soporte.

En el caso de los tembetás se registraron las siguientes variables métricas. En el eje longitudinal: largo, anchos máximo y mínimo del cuerpo; en el eje transversal: largo, ancho máximo y laterales izquierdo y derecho (Figura 2). También se ponderó la porción y orientación de valva utilizada como forma base.

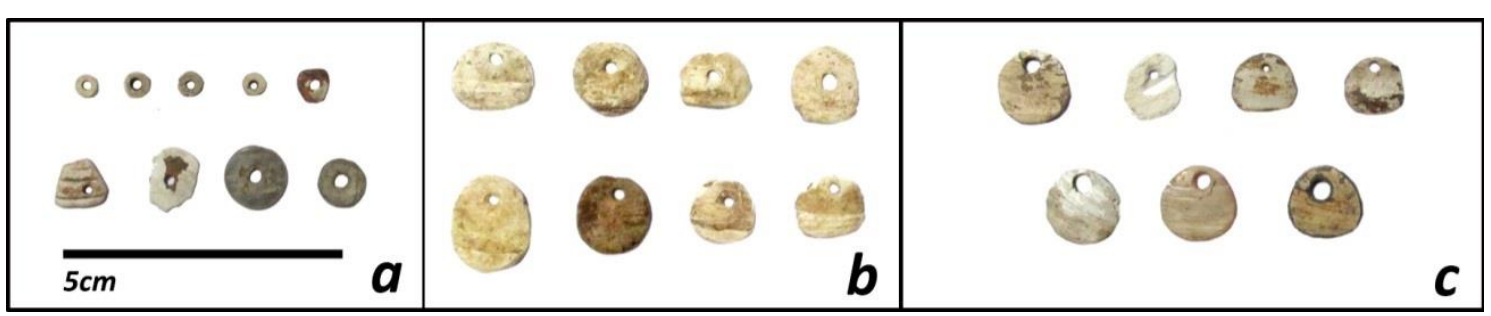

Figura 2. Cuentas de valva. a) La Bellaca 2, b) Cerro Mayor, c) Anahí.

Por último, se describen fragmentos de valva que pudieron haber estado vinculados con la producción de cuentas y tembetás (Figura 3). Siguiendo los criterios de Leonardt (2013) se tuvieron en cuenta: fragmentos abradidos en su contorno, perforados y con fracturas rectas. Si bien sabemos que son amplios los procesos tafonómicos que pueden afectar las superficies de los moluscos imitando modificaciones antrópicas (Kubicka et al. 2017, Szabó 2005), consideramos aquellos fragmentos que, por su tamaño, puedan haber sido parte en el proceso de manufactura de los artefactos aquí discutidos. Diferentes organismos generan perforaciones naturales al adherirse a la superficie externa de las valvas, pero esto no implica descartar la posibilidad de que los restos perforados naturalmente hayan sido reclamados para la elaboración de cuentas (Kubicka et al. 2017, Szabó 2005). Consideramos los fragmentos con fracturas rectas que atraviesan las líneas de crecimiento la valva ya que por naturaleza las mismas se fracturan siguiendo aquellas como líneas de debilidad (Szabó 2005). 

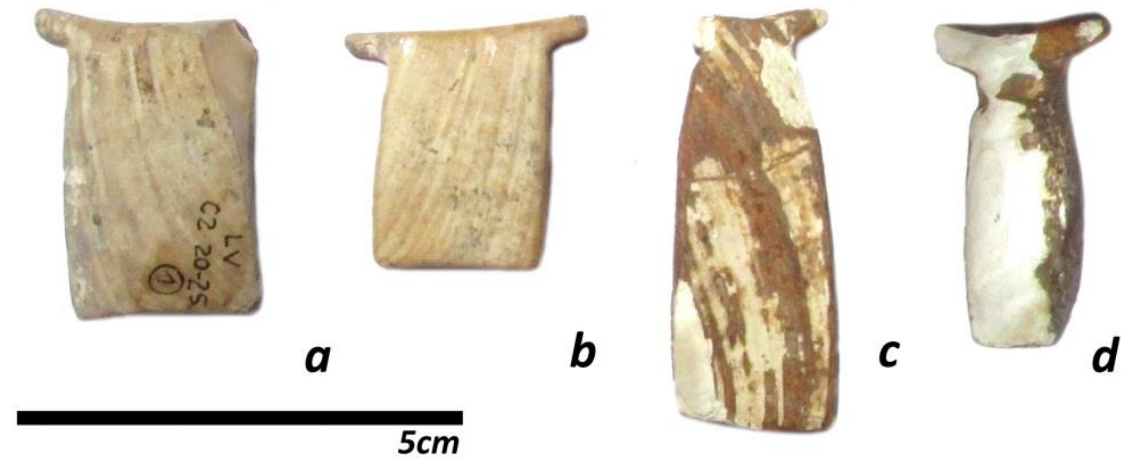

Figura 3. Tembetás. a) Las Vizcacheras, b) La Bellaca 1, c) Cerro Lutz, d) El Cazador 3.

\section{Resultados}

Cuentas

Se registran un total de 42 cuentas elaboradas sobre exoesqueletos de moluscos. Las cuentas provienen de los sitios Anahí ( $n=7)$, Cerro Lutz $(n=4)$, Cerro Mayor $(n=9)$, El Cazador $3(\mathrm{n}=1)$, Guazunambí $(\mathrm{n}=3)$, La Bellaca sitio $2(\mathrm{n}=13)$, Las Ánimas $(\mathrm{n}=1)$, Las Vizcacheras $(n=1)$, Punta Canal $(n=3)$ (Tabla 1, Figura 1). En estos tres últimos casos se trata de piezas aisladas ${ }^{1}$ pero, en los restantes, la mayoría se agrupa por cuadrícula y nivel de extracción (Tabla 2). Esto sugiere la posibilidad que se trate de piezas que se encontraban articuladas en un arreglo mayor, como puede ser un collar. La única excepción la encontramos en el sitio Cerro Lutz donde cada cuenta proviene de un sector de excavación y niveles diferentes. En Cerro Mayor fueron halladas en un contexto de inhumación, mientras que en los restantes sitios fueron recuperadas de contextos domésticos. En los sitios Las Ánimas y Cerro Lutz, las cuentas provienen de las capas superiores al nivel de entierros.

Si bien en la mayoría de los casos no puede identificarse la especie utilizada como soporte, muy probablemente se trate de moluscos bivalvos de origen fluvial disponibles localmente, como es el caso de Diplodon sp. una de las especies más representada en el registro arqueológico (Chiri 1972, Loponte 2008, Loponte et al. este volumen, Parisi 2013, Torres 1911) (Figura 4). Dentro de los concheros, aunque con una frecuencia mucho más baja, también suelen registrarse ejemplares pertenecientes a la familia Ampullariidae. Son gasterópodos de agua dulce de amplia distribución en Argentina y en otras partes de mundo (Berthold 1991, Hayes et al. 2009). En la cuenca del Paraná y del Uruguay, uno de los ampuláridos más comunes es Pomacea maculata (Figura 4b), cuyo tamaño la convierte en una potencial fuente de materia prima. Por último, debe mencionarse el caso del género Megalobulimus (Figura 4), caracoles terrestres de gran tamaño pertenecientes a la subfamilia Megalobuliminae (Strophocheilidae) con amplia distribución en América del Sur (Bouchet y Rocroi 2005). En la muestra aquí analizada, es posible que las cuentas de Cerro Mayor hayan sido confeccionadas sobre esta especie preservando el labio interno como rasgo que otorga un sentido estético particular. 


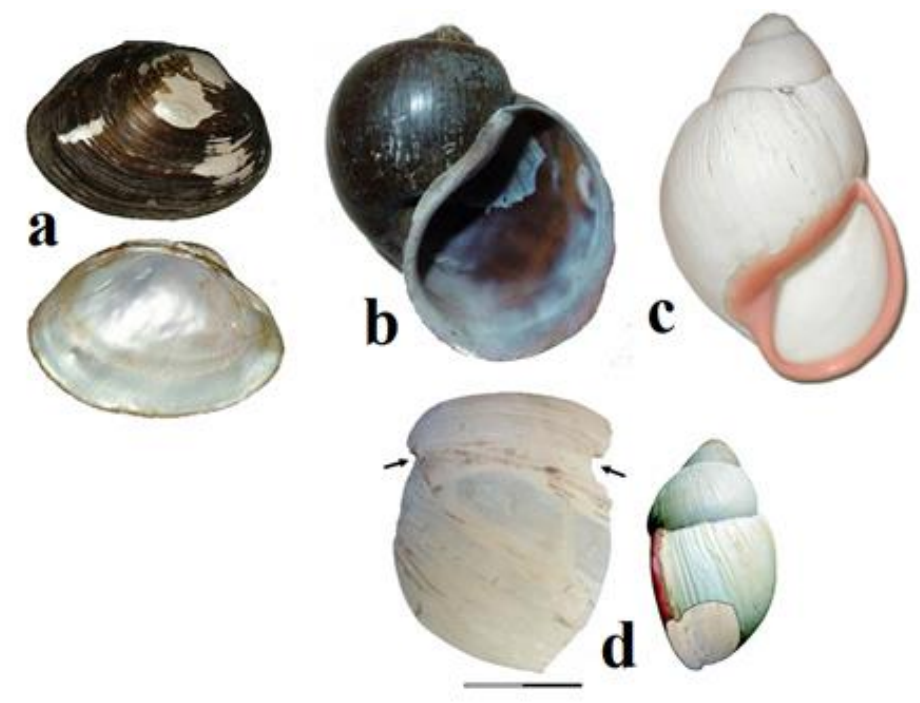

Figura 4. Exoesqueletos de especies de moluscos discutidos en el trabajo: a) Diplodon sp., b) Pomacea maculata; c) Megalobulimus actual, d) artefacto en Megalobulimus recuperado en el sitio Hunter.

En todos los casos se trata de cuentas xenomorfas, es decir, completamente modificadas en su forma natural (Figura 2). Las variantes circulares/subcirculares dominan todos los conjuntos artefactuales (ver Tabla 2; Figura 5). En los sitios Anahí y Guazunambí las cuentas circulares/subcirculares están acompañadas de una irregular; y en Cerro Mayor, de una oval. Más allá de esto, los conjuntos presentan un alto grado de homogeneidad intrasitio, siendo notorio el caso de Cerro Mayor donde todas las cuentas conservan parte del labio interno del exoesqueleto en el sector opuesto a la perforación. Esto refuerza la idea de que las piezas pertenecen a un mismo arreglo tipo collar.

\begin{tabular}{|c|c|c|c|c|c|c|c|c|c|c|}
\hline \multirow[b]{2}{*}{ Pieza } & \multirow[b]{2}{*}{ Cuadrícula } & \multirow[b]{2}{*}{ Nivel } & \multirow[b]{2}{*}{ Diámetro/largo } & \multirow[b]{2}{*}{ Ancho } & \multirow[b]{2}{*}{ Espesor } & \multirow[b]{2}{*}{ Contorno } & \multicolumn{4}{|c|}{ Perforación } \\
\hline & & & & & & & diámetro & tipo & cara inicio & ubicación \\
\hline A-1 & G10 & $35-40$ & 14 & - & 1.78 & circular & 2.94 & cónica & interna & desplazada completa \\
\hline A-2 & G12 & $30-35$ & 13,13 & 10,41 & 1.47 & irregular & 1.67 & cónica & externa & desplazada completa \\
\hline $\mathrm{A}-3$ & G12 & $30-35$ & 14,04 & - & 1.67 & circular & 3.48 & indet & indet & desplazada completa \\
\hline A-4 & G12 & $30-35$ & 14,04 & - & 1.65 & circular & 2,68 & indet & indet & desplazada completa \\
\hline A-5 & G12 & $30-35$ & 14,12 & - & 1.82 & circular & 3.46 & cónica & interna & desvlazada comvleta \\
\hline A-6 & G12 & $30-35$ & 12,06 & - & 1.57 & subcircular & 1.07 & cónica & interna & desplazada completa \\
\hline A-7 & G12 & $30-35$ & 10.8 & - & 1.25 & circular & 1.96 & cónica & interna & desplazada completa \\
\hline PC-1 & $1 \mathrm{~F} / \mathrm{G}$ & $0-10$ & 12,95 & - & 1.94 & subcircular & 2,04 & cónica & interna & desplazada comvleta \\
\hline PC-2 & $1 \mathrm{~F} / \mathrm{G}$ & $0-30$ & 12,58 & - & 1,94 & subcircular & 2,01 & indet & indet & desplazada completa \\
\hline PC-3 & $1 \mathrm{~F} / \mathrm{G}$ & $0-30$ & 13.87 & - & 1.53 & subcircular & 2,31 & indet & indet & desplazada completa \\
\hline Gz-1 & sin datos & sin datos & 12,45 & - & 2,15 & circular & 1,82 & cónica & interna & desplazada completa \\
\hline Gz-2 & sin datos & sin datos & 12 & - & 1,99 & subcircular & 1.46 & cónica & interna & desplazada completa \\
\hline Gz-3 & sin datos & sin datos & 14,41 & 14.68 & 1.43 & irregular & 1.86 & cónica & interna & centrada \\
\hline CL-1 & 2(sector $Y$ ) & $20-25$ & 7.65 & - & 1,2 & circular & 1,68 & cónica & interna & centrada \\
\hline CL-2 & 2(sector A) & $35-40$ & 8.44 & 11.14 & 0.79 & fragmentada & 1.96 & fragmentada & fragmentada & desplazada completa \\
\hline CL-3 & 2(sector Z) & 1015 & 9.51 & - & 1,53 & subcircular & 1,84 & \begin{tabular}{|l|} 
cónica \\
\end{tabular} & interna & desplazada \\
\hline CL-4 & E9 & $15-20$ & 16,01 & - & 1,94 & circular & 2,67 & cónica & interna & desplazada \\
\hline CM1 & sondeo 1 & $2,20-2,30$ & 13,69 & - & 1,93 & subcircular & 2,61 & cónica & interna & centrada \\
\hline $\mathrm{CM} 2$ & sondeo1 & $2,20-2,30$ & 13.79 & - & 2.59 & subcircular & 2,04 & cónica & interna & desplazada completa \\
\hline $\mathrm{CM} 3$ & sondeo 1 & $2,20-2,30$ & 14,36 & - & 1,97 & subcircular & 2,12 & cónica & interna & desplazada \\
\hline CM4 & sondeo 1 & $2,20-2,30$ & 11,64 & - & 1.62 & circular & 1.74 & bicónica & interna & desplazada \\
\hline CM5 & sondeo 1 & $2,20-2,30$ & 13,06 & - & 2,45 & subcircular & 1,99 & cónica & interna & desplazada completa \\
\hline CM6 & sondeo 1 & sin datos & 12,44 & - & 1.59 & subcircular & 1.51 & bicónica & interna & desplazada \\
\hline CM7 & sondeo 1 & sin datos & 12,47 & - & 1,7 & subcircular & 1,94 & cónica & interna & desplazada \\
\hline CM8 & sondeo 1 & sin datos & 17.24 & 14.22 & 2.11 & oval & 1.55 & bicónica & interna & desplazada completa \\
\hline CM9 & sondeo 1 & $1,00-1,10$ & 21,2 & - & 1,2 & circular & 1,89 & cónica & interna & desplazada completa \\
\hline
\end{tabular}

Tabla 2. Variables métricas y morfológicas consideradas del conjunto de cuentas. 


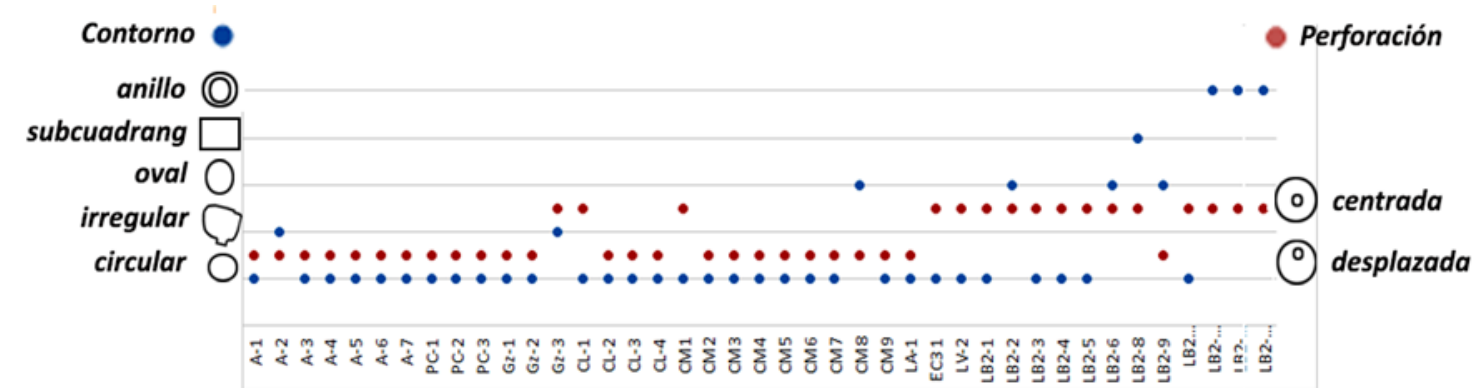

Figura 5. Distribución de variables morfológicas de contorno y ubicación de la perforación en el conjunto de cuentas.

El conjunto de La Bellaca 2 reviste mayor variabilidad morfológica con cuentas circulares, anillos, y subcuadrangulares (Figura 6). Estas últimas presentan sus contornos redondeados lo que sugiere que se trata de piezas terminadas y no en proceso de transformación. Es una posibilidad que los mencionados anillos hayan sido utilizados como adornos en la vestimenta ya que uno de ellos (LB2 12) presenta una huella que lo atraviesa transversalmente y que sugiere un desgaste por una atadura transversal (Figura 6b). Además, en una de las cuentas subcuadrangulares (LB2 2) se resalta el periostraco posiblemente aprovechado para conferir a este elemento un sentido especial (Figura 6a).

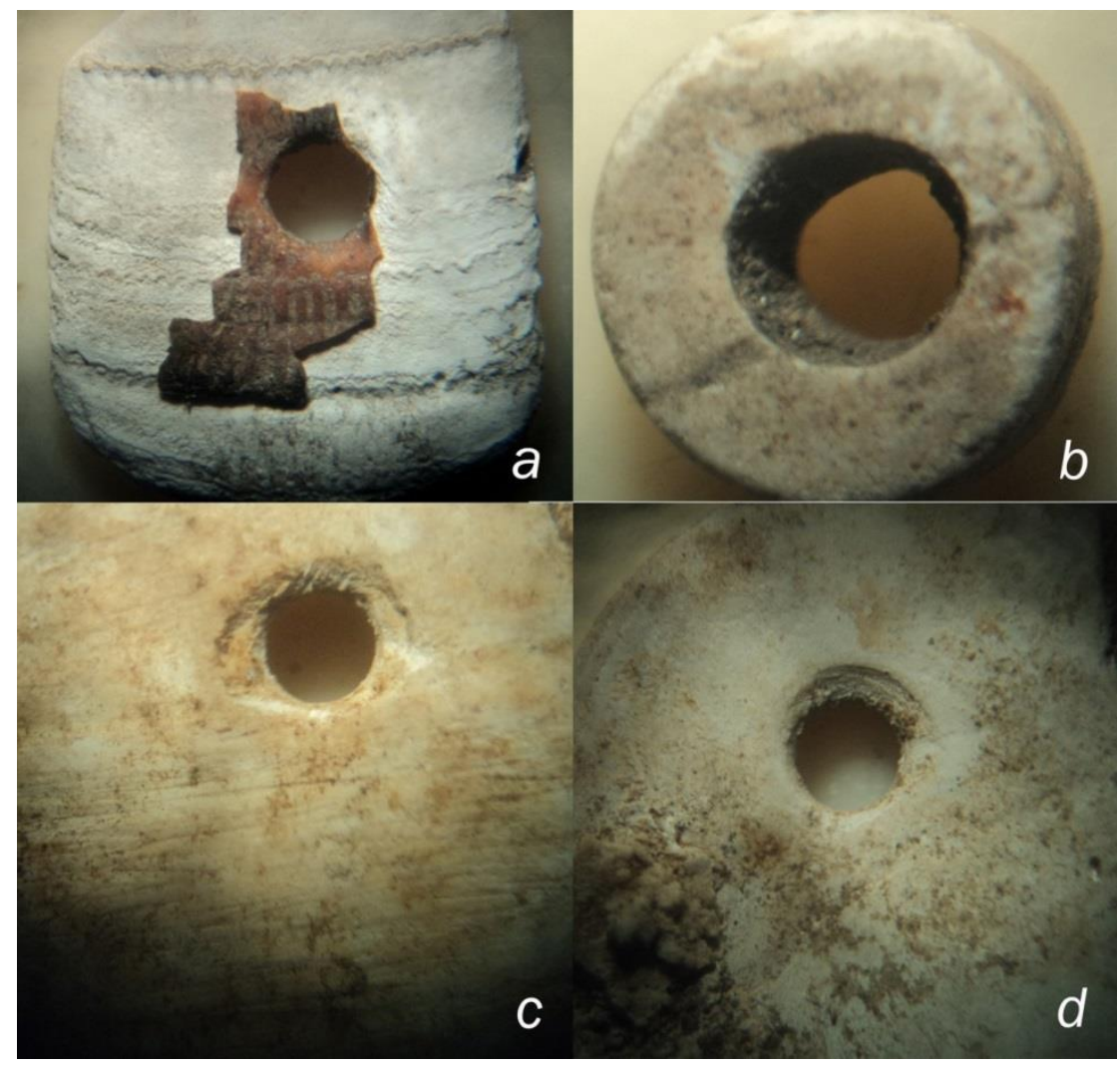

Figura 6. Imágenes obtenidas en lupa binocular a) LB2 2, observar el detalle del periostraco, b) LB2 12, marca transversal superpuesta a perforación, c) CM8 cara externa, d) CM8 cara interna. 
Las variables métricas se grafican en la Figura 7 (ver también Tabla 2). Allí se observa cómo se agrupan las piezas de cada sitio con medidas relativamente estandarizadas a nivel intrasitio, que, a su vez, presentan valores similares entre los conjuntos. La muestra de La Bellaca 2, por su parte, es nuevamente la de mayor variabilidad métrica, distanciándose de los restantes conjuntos.

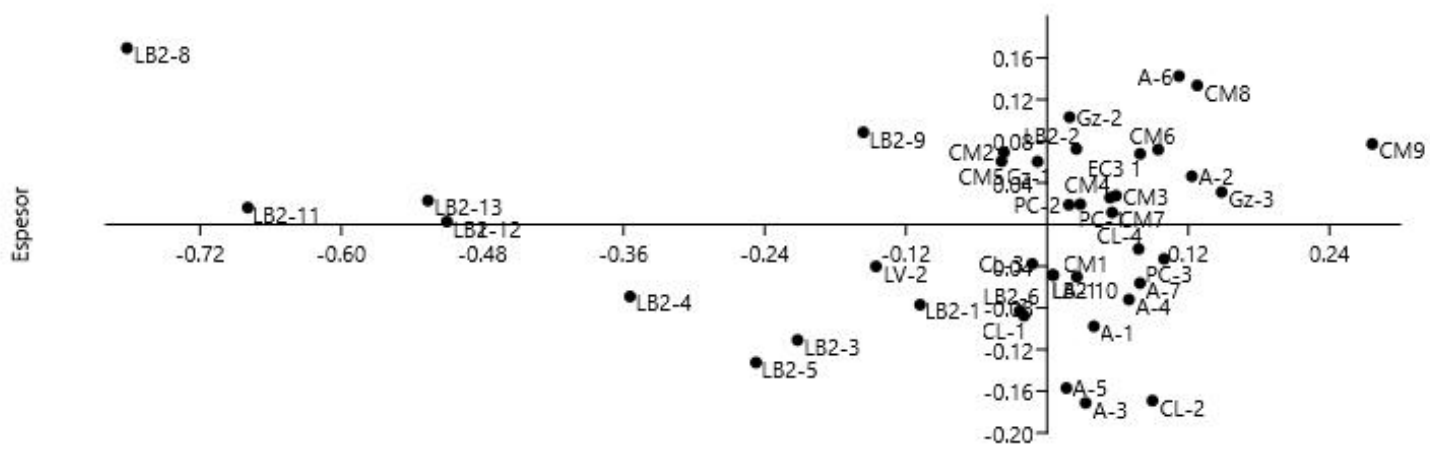

Diametro/Largo

Figura 7. Gráfico de correspondencia en variables métricas de las cuentas.

En la mayoría de los casos la perforación es desplazada del centro. El conjunto de La Bellaca 2 marca la diferencia dado que, salvo en un caso, todas las perforaciones de sus cuentas son centradas (Tabla 2). Independientemente de esto, cuando puede determinarse la cara de inicio de la perforación, salvo un caso, todas están hechas desde la cara interna, lo cual confirma la naturaleza antrópica de las mismas (ver Fragmentos perforados).

A su vez, el $63 \%$ de la muestra tiene perforaciones cónicas y 13\% bicónicas, siendo el $24 \%$ restante, indeterminado. Ambas variantes se encuentran únicamente en los conjuntos de Cerro Mayor y La Bellaca 2, mientras que en los restantes sólo se registraron perforaciones cónicas. Las perforaciones tienen todas entre 1 y 3,5mm, siendo su media 1,85 y su desvío estándar 0,57. En síntesis, los patrones de regularidad/irregularidad observados en la estructura morfológica de las cuentas se ven reflejados en la estructura métrica de los conjuntos.

Tembetás

En el área de estudio recuperamos nueve tembetás de los sitios Cerro Lutz $(n=3)$, El Cazador $3(n=2)$, Guazunambí $(n=1)$, La Bellaca $1(n=1)$, Las Vizcacheras $(n=1)$ y Punta Canal $(\mathrm{n}=1)$. En estos casos como soporte se utilizó Diplodon sp., seleccionando ejemplares espesos, con un valor medio de casi $6 \mathrm{~mm}$ y llegando en algunos casos hasta los $9 \mathrm{~mm}$ (Tabla 3). Todos los tembetás están formatizados de manera que su eje longitudinal sigue los anillos de crecimiento de la valva. Esto da cuenta de un manejo de las propiedades de la materia prima malacológica. No sólo es menos costoso utilizar la línea de debilidad de la valva para dar forma al borde más extenso de los tembetás (eje longitudinal), sino que, además, de esta manera el objeto es menos frágil. 


\begin{tabular}{|c|c|c|c|c|c|c|c|c|c|}
\hline \multirow[b]{2}{*}{ Pieza } & \multirow[b]{2}{*}{$\begin{array}{l}\text { Sentido } \\
\text { valva }\end{array}$} & \multirow[b]{2}{*}{$\begin{array}{c}\text { Largo eje } \\
\text { longitudinal }\end{array}$} & \multirow[b]{2}{*}{$\begin{array}{c}\text { Ancho eje } \\
\text { longitudinal }\end{array}$} & \multirow[b]{2}{*}{$\begin{array}{l}\text { Ancho } \\
\text { cuello }\end{array}$} & \multirow[b]{2}{*}{$\begin{array}{l}\text { Largo/ } \\
\text { Ancho }\end{array}$} & \multirow[b]{2}{*}{ Espesor } & \multirow[b]{2}{*}{$\begin{array}{l}\text { Largo eje } \\
\text { transversal }\end{array}$} & \multicolumn{2}{|c|}{$\begin{array}{l}\text { Medida de los lados } \\
\text { transversales }\end{array}$} \\
\hline & & & & & & & & Izq. & Der \\
\hline CL1 & Transv. & 38,65 & 11,91 & 9,81 & 3,94 & 3,7 & Fract. & Fract. & 7,32 \\
\hline CL2 & Transv. & 44,63 & 17,36 & 10,27 & 4,35 & 5 & Fract. & Fract. & 5,39 \\
\hline CL3 & Transv. & 32,78 & 11,11 & 11,28 & 2,91 & 6,6 & Fract. & Fract. & 5,1 \\
\hline EC3 & Transv. & 37,27 & 10,93 & 9,25 & 4,03 & 9,3 & 20,52 & 7,16 & 7,33 \\
\hline EC3-1 & Transv. & 37,87 & 10,86 & 11,55 & 3,28 & 7,3 & 19,14 & 5,74 & 5 \\
\hline GZ1 & Transv. & 40,09 & 12,6 & 11,13 & 3,60 & 3,6 & Fract. & 3,86 & Fract. \\
\hline LB1 & Transv. & 25,51 & 18,34 & 17,18 & 1,48 & 4,5 & 26,34 & 4,69 & Fract. \\
\hline LV1 & Transv. & 30,69 & 19,5 & 19,15 & 1,60 & 9,1 & Fract. & 4,96 & Fract. \\
\hline PC 1 & Indet. & Fract. & 9,56 & 8,96 & Fract. & 2,9 & Fract. & Fract. & 4,26 \\
\hline $\mathrm{X}$ & - & 35,94 & 13,57 & 12,06 & 3,15 & 5,78 & 22,00 & 5,28 & 5,88 \\
\hline de & - & 6,00 & 3,75 & 3,61 & 1,09 & 2,40 & 3,82 & 1,25 & 1,38 \\
\hline
\end{tabular}

Tabla 3. Variables morfológicas y métricas consideradas en el análisis de los tembetás

Considerando la morfología y variables métricas, identificamos dos tipos de tembetás: uno delgado, donde la relación entre el largo y el ancho máximo es $\geq 1,5 ; \mathrm{y}$ otro ancho, donde esta relación es $\leq 1,5$ (Tabla 3). En la Figura 8 los ejemplares se agrupan por sitio, distanciándose los de La Bellaca 1 y Las Vizcacheras que son, justamente, los dos tembetás anchos.

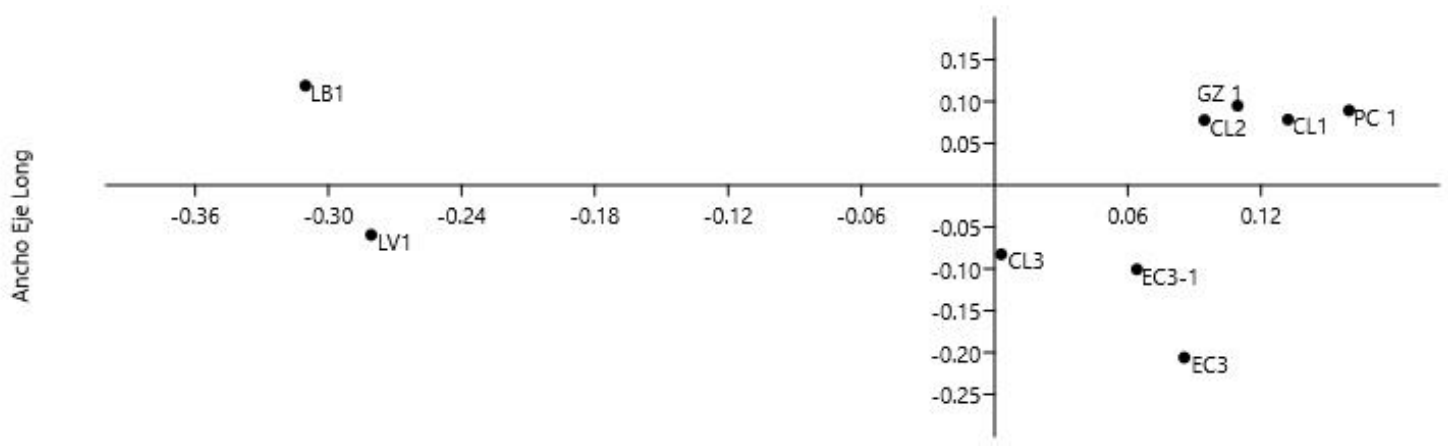

Largo Eje Long

Figura 8. Gráfico de correspondencia de variables métricas de tembetás.

Fragmentos de valvas modificadas

En los conjuntos arqueológicos se han recuperado varios fragmentos de valvas de Diplodon sp. que presentan contornos abradidos, perforaciones, muescas o fracturas rectas que merecen una consideración en este trabajo (Figura 9). 


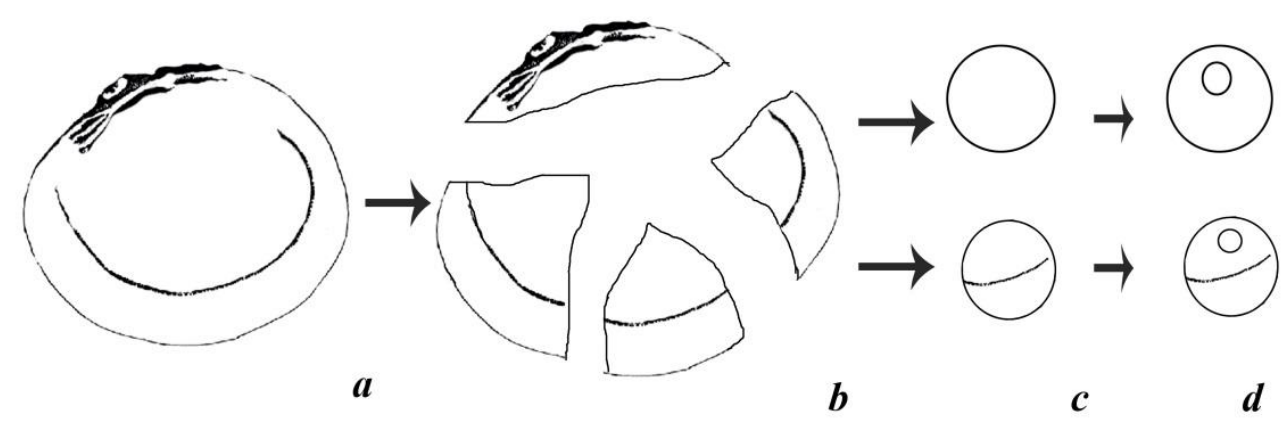

Figura 9. Fragmentos de valva modificadas. a) fragmentos abradidos, b) fragmento con perforación natural, c) fragmentos con fracturas rectas.

Fragmentos abradidos

Se recuperaron nueve fragmentos cuyos contornos fueron abradidos para lograr una forma regular: dos en Anahí, cinco en Punta Canal, uno en Guazunambí y uno en La Bellaca 2. Excepto el de La Bellaca 2 que es de forma cuadrangular, los restantes tienen un contorno circular. Su estructura métrica (diámetro/largo y ancho y espesor) se ajusta a los valores de las cuentas perforadas, por lo que podemos considerarlos como preformas de las mismas. En la Figura 10 se propone la cadena operativa de la manufactura de las cuentas. A partir de una valva entera (Figura 10a), se obtienen fragmentos por percusión (Figura 10b). Esta es la manera más económica de obtener fragmentos, siempre que no se persiga la regularidad de los mismos. Estos fragmentos son abradidos con una materia prima de grano grueso para obtener un contorno uniforme (Figura 10c). Luego son perforados (Figura 10d) con un instrumento punzante. En otro trabajo presentamos resultados parciales de experimentaciones de este tipo realizadas con materias primas líticas disponibles en el área de estudio. Se utilizó un núcleo de arenisca silicificada para fracturar la valva de Dipolodon sp. y regularizar su contorno hasta obtener discos (Silvestre y Buc 2015), luego, ápices de calcedonia fueron utilizados para realizar las perforaciones. Las actividades mencionadas fueron realizadas de manera sencilla por lo cual es factible pensar en la manufactura local de las cuentas.

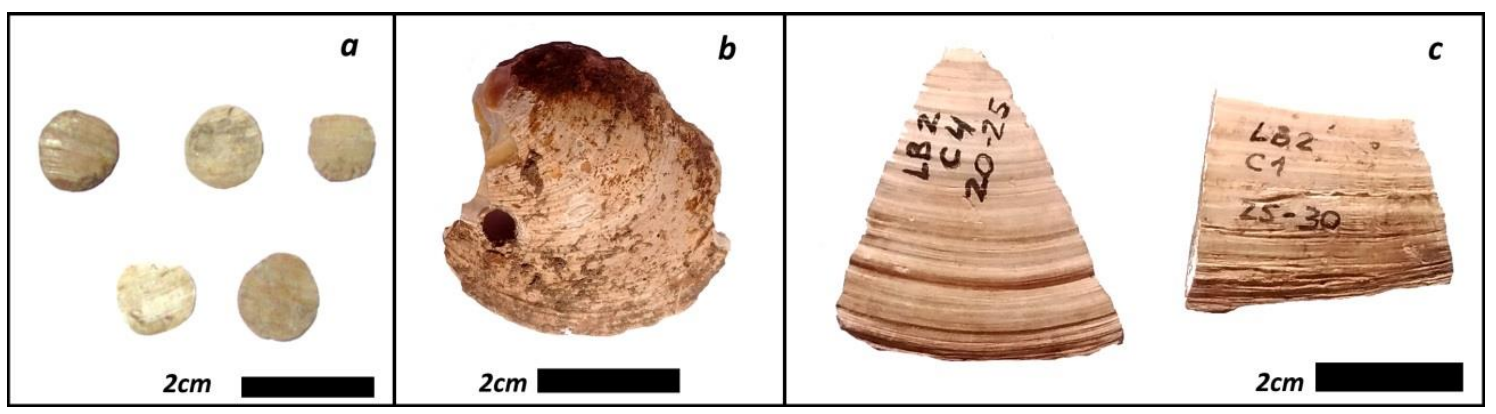

Figura 10. Cadena operativa propuesta para la obtención de cuentas perforadas. 
Fragmentos perforados

Una gran cantidad de fragmentos o valvas completas con perforaciones naturales fueron recuperadas del sitio Cerro Lutz $(n=11)$. Como mencionamos, diferentes organismos predan los moluscos a través de sus valvas dejando, como consecuencia, perforaciones sobre el periostraco. Estas perforaciones se distinguen por ser circulares o ligeramente alargadas, cónicas e iniciadas desde la cara externa del exoesqueleto. En promedio tienen perforaciones más grandes que las registradas en las cuentas $(X=5 \mathrm{~mm})$ por lo que descartamos la idea de que estos restos hayan sido reclamados para la fabricación de cuentas, aprovechando la perforación natural. Esta misma perforación es señal de la pérdida de valor del molusco como recurso alimenticio. Si bien podemos considerar su ingreso como parte de la captura masiva de los recursos con redes, creemos que es necesario llamar la atención sobre su presencia en un sitio arqueológico (Szabó 2005) de manera de confundirlas con las variantes antrópicas.

Fragmentos con muescas

En tres fragmentos de valva provenientes de los sitios El Cazador 3, Anahí y La Bellaca 2 se observaron muescas que podrían ser antrópicas.

Fragmentos con fracturas rectas

Fragmentos con uno o dos bordes con fracturas rectas que atraviesan transversalmente los anillos de crecimiento de las valvas fueron recuperados en Cerro Lutz, La Bellaca 2 y Las Vizcacheras $(n=20)$. Como mencionamos, las fracturas naturales ocurren siguiendo las líneas de debilidad por lo que consideramos que parte de ellos (sobre todo los fragmentos espesos) pueden ser producto de fracturas intencionales involucradas en la formatización de artefactos, como pueden ser los tembetás. A partir de una valva entera (Figura 11a) se obtuvieron formas base mediante corte o fracturas controladas (Figura 11b-c) que permitieron obtener módulos espesos cuyo eje mayor sigue las líneas de crecimiento de las valvas pero su eje menor las atraviesa. Finalmente se realizan las muescas que otorgan la forma característica a los tembetás (Figura 11d).

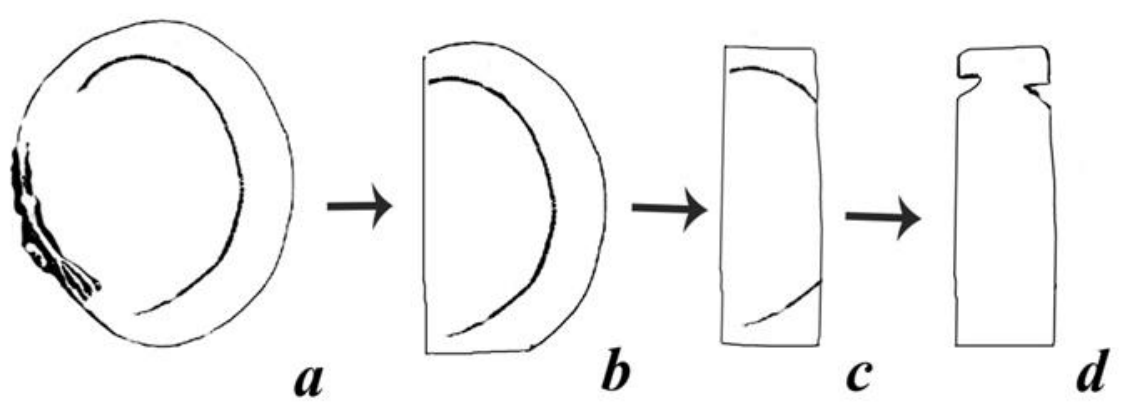

Figura 11. Cadena operativa propuesta para la formatización de tembetás 


\section{Discusión}

Las cuentas son los adornos más representados en cada sitio discutido en este trabajo y a nivel regional en la cuenca de los ríos Paraná y Uruguay. Esta sobrerrepresentación está vinculada, en principio por el hecho de que las cuentas funcionan agregadas en un arreglo tipo collar. Esto explica en buena medida la estandarización a nivel intrasitio, sobre todo teniendo en cuenta los contextos de hallazgo de estos conjuntos. Pero también vemos que a nivel regional se repite una forma general de cuenta circular o subcircular con una estructura métrica similar. Salvo por la muestra de La Bellaca 2 que tiene características disímiles, en los restantes conjuntos el desvío estándar en las variables métricas es $<5$ (DE diámetro máximo: 2,9; DE espesor: 0,39), una variación imperceptible a la experiencia humana (Eerkens 2000), más aún si la consideramos distribuida en una escala espacial y temporal amplia. La diferenciación del conjunto de La Bellaca 2 puede explicarse por la diferencia temporal también de este conjunto ya que es el único fechado en el extremo más tardío de la distribución cronológica. No descartamos la posibilidad de que conforme aumentó la población en el área de estudio y se saturaba el paisaje, los procesos de diferenciación social se volvieran más complejos generando la aparición de nuevas variables.

La cantidad y la estandarización son propiedades de los objetos de adorno (Kuhn y Stiner 2007a) que, en este caso, se replica por toda la cuenca de los ríos Paraná y Uruguay con la presencia de cuentas subcirculares de sección plana (ver por ejemplo Hilbert 1991, Lothrop 1932). En la regularidad del registro también debemos mencionar la selección de materia prima. En los casos aquí analizados no podemos distinguir la especie utilizada, pero esto también es parte de una intencionalidad, se logra la uniformidad a partir de la selección de especies locales altamente modificadas. Sólo en el caso de Cerro Mayor podemos sugerir la utilización de una especie en particular como es Megalobulimus sp. Algunos otros casos particulares incluyen elementos recuperados en el sitio Arroyo Sarandí. Se trata de un collar cuyas cuentas automorfas están logradas a partir gasterópodos marinos (Urosalpinx haneti; Acosta et al. 2015, 2017, Bonomo 2013, Lothrop 1932) y otras cuentas planas hechas sobre Glycymeris longior (Lothrop 1932, Bonomo et al. 2009, Acosta et al. 2015). En la colección Almeida proveniente del sitio Cerro San Lorenzo 2, situado en el sur de Entre Ríos, se han identificado 21 cuentas manufacturadas sobre el labio columelar de Megalobulimus sp. (Castro 2017). Dentro de la misma colección, aunque se desconoce la procedencia, otras cuentas fueron hechas con fragmentos de labio interno de la misma especie (ver Castro 2017: Figura 7.13: 322). Este taxón es utilizado como materia prima en otras regiones, por ejemplo, en diversos sitios arqueológicos de la provincia de Córdoba se han registrado adornos elaborados sobre Megalobulimus lorentzianus (ver Boretto et al. 2018, Pastor et al. 2017). Un posible ornamento confeccionado sobre un fragmento de esta especie (ver Figura 4d) ha sido recientemente identificado en el sitio arqueológico Hunter situado en la Pampa ondulada (Loponte et al. 2010), área adyacente al humedal del Paraná inferior. 
En el caso de los tembetás, en primer lugar notamos que, salvo la excepción de Punta Canal, fueron recuperados en sitios con cerámica lisa (tal como fuera notado por Loponte 2008). Al interior de este grupo, identificamos dos variantes artefactuales: una de cuerpo más delgado y la otra, más ancha. Si bien es una posibilidad que la variación responda restricciones sociales, debemos considerar que el tamaño de los tembetás puede variar de acuerdo con el individuo que lo porta. En el Paraná inferior y en el litoral en general, los adornos labiales fueron tempranamente reconocidos $\mathrm{y}$ relacionados con los guaraníes en la literatura arqueológica y etnohistórica (e.g. Ambrosetti 1895, Outes 1918, Schaden 1974, Staden 1930 para poblaciones amazónicas). Sin embargo, los aquí estudiados corresponden a poblaciones de cazadores recolectores locales (Loponte 2008) y son distintos morfológicamente de aquellos recuperados en contextos guaraníes y que fueron elaborados sobre cuarzo y resina vegetal (Loponte y Acosta 2013). Estos constituyeron un símbolo típico de masculinidad que tiene su inicio en un rito de pasaje de los individuos de la infancia a la pubertad (Müller 1989). Si bien para las poblaciones locales existe información etnohistórica que avala el uso de tembetás (Ramírez, en Madero 19392), es difícil precisar la simbología que tuvieron para estos grupos. Téngase en cuenta que existen contextos etnográficos, en donde los tembetás son indistintamente utilizados por hombres y mujeres, y suelen tener funciones socialmente diferentes (Iribarren Charlin 1950, Keddie 1989). Adornos labiales similares a los aquí estudiados han sido registrados en las colecciones museísticas generadas por Carlos Maeso Tognochi y Manuel Almeida. La primera de ellas corresponde al sitio La Blanqueada situado sobre la margen izquierda del río Negro, próximo a su desembocadura en el río Uruguay y se encuentra depositada en el Museo Nacional de Antropología de Montevideo. Es el mismo Maeso Tognochi quien señala el hallazgo en dicho sitio de un "barbote trabajado en una valva de molusco", además de valvas perforadas y de un gancho propulsor, aparentemente asociados a un entierro primario de un individuo adulto (Maeso Tognochi 1977: 186). Posteriormente, y dentro de la misma colección del mencionado sitio, Hilbert (1991, ver también Gascue et al. en este volumen) reconoce la existencia de dos tembetás más. Según el autor, las tres piezas miden entre 7 y 4,5 cm de largo (Figura 12) (Hilbert 1991: 42. Figura 120), por lo que el más largo de estos tembetás sería un outlier dentro de los conjuntos aquí analizados (ver Tabla 3). En la colección Almeida se identificaron dos ejemplares (Figura 12); que provienen del "Sambaquí Puerto Landa" (Castro 2017), sitio que se encuentra dentro del departamento de Gualeguaychú (provincia de Entre Ríos), visitado y estudiado por Torres (1911) y luego por Greslebin (1931). De acuerdo a lo publicado, los rangos de tamaño de estas piezas son semejantes a los de los conjuntos analizados en este trabajo, asemejándose a las variantes angostas de los tembetás. Además, en los casos que puede identificarse, la valva está utilizada con las líneas de crecimiento en sentido longitudinal. 
Además de estas categorías de adornos, en varios sitios hemos identificado fragmentos de valva abradidos que tienen la misma estructura métrica que las cuentas por lo que pensamos que serían preformas o formas base. Asimismo, se identificaron elementos con fracturas y muescas de los cuales no descartamos su vinculación con la producción de artefactos, como pueden ser los tembetás. Si bien estos ejemplares requieren de estudios microscópicos específicos, creemos que parte de ellos pueden interpretarse como subproductos o formas bases generadas para la elaboración de los artefactos discutidos en este trabajo.
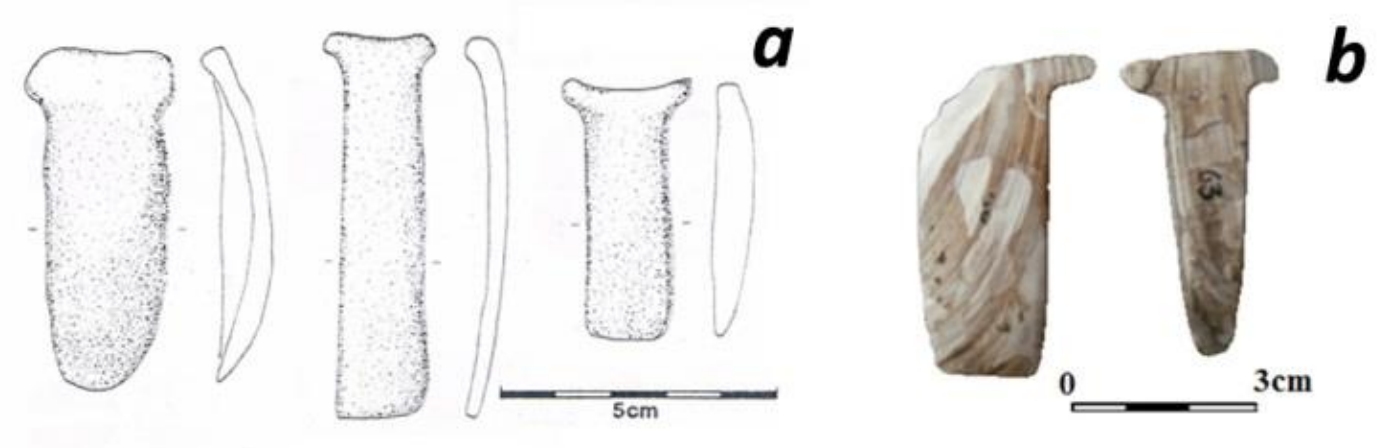

Figura 12. Tembetás publicados por otros autores para el área de estudio A) Hilbert (1991:42) para la colección Maeso Tognochi; b) Castro (2017: Figura 713b) para la colección de Sambaquí Puerto Landa

Con respecto a la disponibilidad de materia prima para elaborar los ornamentos de origen local, cabe señalar que, en diversos sitios arqueológicos del HPI, se han identificado niveles con una alta y concentrada densidad de valvas conformando verdaderos concheros (Acosta et al. 201, Chiri 1972, Gónzalez 1947, Greslebin 1931, Torres 1911). Se trata de acumulaciones de origen antrópico, hecho que se verifica por la evidente selectividad taxonómica y tamaños de las valvas, además del grado de desarticulación, fragmentación y su asociación con otros materiales arqueológicos (Parisi 2013, Parisi y Liotta 2010). El taxón dominante en estas concentraciones corresponde al género Diplodon representado por siete especies diferentes que se distribuyen en distintos espacios de la cuenca ParanoPlatense (Torres et al. 2013). Son almejas nacaríferas que habitan y se reproducen en ambientes lóticos y lenticos (Bonetto et al. 1961), lugares en donde generalmente también se ubican la mayoría de los sitios arqueológicos que se encuentran en la cuenca del Paraná inferior. La proximidad espacial de los asentamientos humanos, sumado al bajo riesgo de obtención, indican que los moluscos constituyeron un recurso de muy fácil acceso para los grupos aborígenes, los cuales no solo adquirieron cierta importancia en términos alimenticios (e.g. Chiri 1972, Loponte 2008, Parisi 2013, Parisi y Liotta 2010) sino que también fueron utilizados con diversos fines (Chiri 1972), entre ellos para la confección de adornos como los aquí estudiados. En tal sentido, se ha señalado que las almejas nacaríferas poseen estructuralmente muy buenas propiedades para la fabricación de distintos tipos de 
objetos (Castellanos 1965); a tal punto que en el Paraná medio, a mediados del siglo pasado, para la explotación y comercialización del nácar se extraían unas 2.000 toneladas de valvas por año (Gordillo 2010).

\section{Conclusiones}

Observamos que las cuentas se distribuyen de manera homogénea incluyendo diferentes sectores de la cuenca de los ríos Paraná y Uruguay y sitios que se diferencian en otras líneas de evidencia, como la decoración cerámica y la representación del material lítico (ver arriba). Con excepción del caso de La Bellaca 2, las variaciones morfológicas y métricas registradas puede considerarse reflejo de la producción artesanal que sucede dentro de un patrón y modos de hacer compartidos por transmisión cultural. Esto explica la distribución homogénea de rasgos de la producción artefactual, tales como la forma, diámetro y espesor de las cuentas, así como el tipo de la perforación y su tamaño. Los tembetás, por su parte, tienen una distribución más heterogénea, identificándose en menor frecuencia y en algunos sitios (principalmente con cerámica lisa). En principio registramos dos variantes que no podemos discernir si responden a variaciones individuales o étnicas. Si bien es necesaria la ampliación de la muestra con variantes anchas, la variante angosta explica la mayoría de los casos y se distribuye en la cuenca inferior de los ríos Paraná y Uruguay.

Lo anterior lleva a suponer que cuentas y tembetás son objetos con un diseño simple y confeccionados en materia prima disponible localmente, que pudieron replicarse a nivel regional transmitiendo información emblemática dentro del grupo de pertenencia, como una forma de demarcación etaria, social y/o étnica. Se trata de objetos pequeños, que fueron producidos para ser vistos (Fiore 2011), sean las cuentas integradas en un collar, en un vestido, o el tembetá completando el rostro de las personas. Si bien no descartamos la posibilidad de que algunos elementos fueran obtenidos a través del intercambio entre bandas locales que compartiesen códigos o señales de comunicación similares, creemos que estos objetos fueron producidos localmente utilizando materia prima y conocimientos tecnológicos semejantes para su manufactura.

Agradecimientos: Este trabajo se financió parcialmente con el subsidio PIP 11220150100482CO. Los comentarios realizados por las dos evaluaciones anónimas mejoraron notablemente la claridad del Ms.

\section{Notas}

${ }^{1}$ El conjunto de El Cazador 3 se encuentra en proceso de análisis.

2 Luis Ramírez señala que ciertos grupos de la región "tienen todos horadadas las narices, así hombres como mujeres por tres partes, y las orejas, los hombres horadan los labios por la parte baja" (Ramírez, en Madero 1939: 384, el énfasis es nuestro). 


\section{Bibliografía citada}

Acosta, A.

2005. Zooarqueología de cazadores-recolectores del extremo nororiental de la provincia de Buenos Aires (humedal del río Paraná inferior, Región Pampeana, Argentina). PHD Dissertation, Facultad de Ciencias Naturales y Museo-Universidad Nacional de La Plata, La Plata. MS

Acosta, A., N. Buc y M. N. Davrieux

2015a.Producción y uso de ornamentos en las tierras bajas de Sudamérica: el caso de las poblaciones humanas prehispánicas del extremo meridional de la cuenca del Plata (Argentina). Munibe Antropologia-Arkeologia 66: 309-325.

Acosta, A., N. Buc, M. Ramírez, F. Prevosti, D. Loponte

2015b. Producción y uso de objetos ornamentales elaborados sobre dientes de carnívoros en contextos arqueológicos del humedal del Paraná inferior. Revista del Museo de Antropología de Córdoba 8 (2), 33-46.

Acosta, A., D. Loponte y P. Tchilingurian

2010. Análisis comparativo sobre la estructura y los procesos de formación de los depósitos arqueológicos en el humedal del rio Paraná inferior (delta del Paraná). Arqueología de Cazadores-recolectores en la Cuenca del Plata (ed. por G. Cocco, G. M. Feuillet Terzaghi y L. Campagnolo), pp. 191-208. Centro de Estudios Hispanoamericano, Santa Fe.

Acosta, A., D. Loponte y C. García Esponda

2011. Primer registro de perro doméstico prehispánico (Canis familiaris) entre los grupos cazadores recolectores del humedal de Paraná inferior (Argentina). Antípoda. Revista de Antropología y Arqueología 13: 175-199.

Acosta, A. y B. Mazza

2016. Restos óseos humanos y faunísticos: Su relación en el espacio mortuorio en contextos de cazadores recolectores del humedal del Paraná inferior (Argentina). Pesquisas, Antropologia 72: 185-207.

Acosta, A. y L. Mucciolo

2014. Paisajes arqueofaunísticos: distribución y explotación diferencial de ungulados en el sector centro-oriental de la región pampeana. Arqueología 20 (2): 243-261.

Acosta, A., G. Pastorino y D. Loponte 2017. Registro de moluscos marinos entre cazadores-recolectores del norte de la región Pampeana. Comechingonia 21(1): 233-259. 
Ambrosetti, J. B.

1895. Los cementerios prehistóricos del Alto Paraná (Misiones). Boletín del Instituto Geográfico Argentino XVI: 227-263.

Arrizurieta, M.P., N. Buc, B. Mazza, L. Mucciolo, J. Musali, F. Parisi, D. Pau, M. Pérez, M. Poggi, R. Silvestre

2010. Nuevos aportes a la arqueología del sector continental del humedal del Paraná inferior. Arqueología Argentina en el Bicentenario de la Revolución de Mayo (ed. por J.R. Bárcena y H. Chiavazza), Tomo V, pp. 1793-1798. Universidad Nacional de Mendoza, Mendoza.

Barciela González, V.

2016 El origen del simbolismo en las sociedades paleolíticas: una visión a través de los adornos personales Archivo de Prehistoria Levantina XXXI: 9-26.

Berthold, $\mathrm{T}$.

1991 Vergleichende Anatomie, Phylogenie und historische Biogeographie der Ampullariidae (Mollusca, Gastropoda). Abhandlungen des Naturwissenschaftlichen Vereins in Hamburg (NF) 29: 1-256.

Bliege Bird, R. y E.A. Smith

2005. Signaling Theory, Strategic Interaction, and Symbolic Capital. Current Anthropology 46 (2): 221-248.

Boman, E.

1920 Cementerio indígena en Viluco (Mendoza) posterior a la conquista. Anales del Museo Nacional de Historia Natural de Buenos Aires XXX: 501-559.

Bonetto, A.A., I. Maciel y C. Pignalberi

1961 Algunos factores ecológicos vinculados a la distribución de las náyades en el río Paraná y sus afluentes. Publicación Técnica 12: 167-175.

Bonomo, M.

2013 Reanálisis de la colección de Samuel Lothrop procedente del delta del Paraná. Relaciones de la Sociedad Argentina de Antropología 38 (1), 169-198

Bonomo, M., I. Capdepont y A. Matarrese

2009 Alcances en el estudio de colecciones. Los materiales arqueológicos del Delta del río Paraná depositados en el museo de La Plata (Argentina). Arqueología Suramericana 5 (1): 68-101.

Boretto, G. M., S. Gordillo, A. Izeta, F. Colombo, M. Martinelli y R. Cattáneo 2018. Cuentas ornamentales en un contexto de cazadores-recolectores de la provincia de Córdoba: análisis mineralógico y microestructural de la concha de "Borus". Arqueología 24 (1): 213-223. 
Bouchet, P. y J. P. Rocroi

2005. Classification and Nomenclature of Gastropod Families. Malacologia 47:1-397.

Buc, $\mathrm{N}$.

2012. Tecnología Ósea de Cazadores-Recolectores del Humedal del Paraná Inferior. Bajíos Ribereños Meridionales. Arqueología de la Cuenca del Plata. Series Monográfica III. Instituto Nacional de Antropología y Pensamiento Latinoamericano, Buenos Aires.

Buc, N. y D. Loponte. 2016. Bone tools discussing animal exploitation. The case of Lama guanicoe in the Low Paraná basin. Cuadernos del Instituto Nacional de Antropología y Pensamiento Latinoamericano. Series Especiales 3 (2): 23-53

Buc, N. y R. Silvestre

2010. Distribución de artefactos líticos y óseos en el humedal del Paraná inferior. En:G. Cocco y M.R. Feuillet Terzaghi (Eds.), Arqueología de cazadores-recolectores en la cuenca del Plata. Centro de Estudios Hispanoamericanos, Santa Fe. 171-188.

Castellanos, Z.

1965. Contribución al estudio biológico de almejas nacaríferas del Río de la Plata. Revista del Museo de La Plata 8 (60): 99-147.

Castro, J. C.

2017. Investigaciones arqueológicas en la cuenca media e inferior del río Uruguay (provincia de Entre Ríos). Tesis Doctoral, Facultad de Ciencias Naturales y Museo, Universidad Nacional de La Plata, La Plata.

Chiri, O. C.

1972. Acerca de la utilización de valvas de moluscos y la formación de montículos de valvas en yacimientos arqueológicos del Nordeste argentino. Relaciones de la Sociedad Argentina de Antropología 6: 163-172.

Cimino, A. y G. Pastorino

2007. De conchas y cordones conchiles: procedencia de las valvas utilizadas para la confección de los elementos de adorno del sitio Chenque I. Arqueología en las pampas (ed. por Bayón, C., Pupio, A., González, M. I., Flegenheimer, N. y M. Frére), Tomo I, pp. 385-400. Sociedad Argentina de Antropología, Buenos Aires.

Doello Jurado, M.

1940. Presencia de Moluscos Marinos en los Yacimientos Arqueológicos de Santiago del Estero. Síntesis Malacológica. Relaciones de la Sociedad Argentina de Antropología 2: 123-144.

Eerkens, J.

2000. Practice Makes within $5 \%$ of Perfect: Visual Perception, Motor Skills, and Memory in Artifact Variation. Current Anthropology 41 (4): 663-668. 
Ember, C. y M. Ember

2011. Cultural Anthropology (13th Edition). New Jersey: Prentice Hall. Firth, Raymond 1951 Elements of Soci Organization. London: Routledge.

Fiore, D.

2011. Art in time. Diachronic rates of change in the decoration of bone artefacts from the Beagle Channel region (Tierra del Fuego, Southern South America). Journal of Anthropological Archaeology 30: 484-501.

Flensborg, G.

2017. Análisis tecnomorfológico de adornos, cuentas y otros ornamentos. Arqueología de cazadores-recolectores del curso inferior del río Colorado (provincia de Buenos Aires, Argentina) Aportes al conocimiento de las ocupaciones humanas pampeano-patagónicas (ed. por Gustavo Martínez), Serie monográfica - número 6, pp. 230-329. UNICEN, Tandil.

González, A. R.

1947. Investigaciones arqueológicas en las nacientes del Paraná Pavón. Universidad Nacional de Córdoba.

Greslebin, H. R.

1931. La estructura de los túmulos indígenas prehispánicos del departamento de Gualeguaychú provincia de Entre Ríos, República Argentina. Revista de la Sociedad de Amigos de la Arqueología 5: 5-51.

Gordillo, S.

2010. Las almejas nacaríferas de la cuenca Parano-platense: patrimonio natural y cultural de Sudamérica. Cartilla de Difusión No 15. Museo Provincial de Ciencias Naturales "Florentino Ameghino". http://www.unl.edu.ar/santafe/ museocn/cartillas/CARTILLA_15_\%20 ALMEJAS_NACARIFERAS.pdf [en línea].

Gordillo, S. y M. Fabra

2014. El uso de almejas y caracoles por parte de poblaciones prehispánicas que habitaron el Mar de Ansenuza en el norte cordobés. Revista del Museo Histórico Municipal La Para, Memorias del Pueblo Digital 1 (1): 5-17.

Hayes, K. A., R. H. Cowie y S. C. Thiengo

2009. A global phylogeny of apple snails: Gondwanan origin, generic relationships, and the influence of outgroup choice (Caenogastropoda: Ampullariidae). Biological Journal of the Linnean Society 98: 61-76.

Hilbert, $\mathrm{K}$.

1991 Aspectos de la Arqueología en el Uruguay. Ava Materialen 44, Verlang Philipp Von Zabern, Mainz am Rhein. 
Iribarren Charlin, J.

1950 Notas preliminares sobre la dispersion continental de un adorno del labio en los pueblos aborígenes: el bezote, labret o tembeta. Ovalle, Chile.

Keddie, G.

1989. Symbolism and Context: The World History of the Labret and Cultural Diffusion on the Pacific Rim. Trabajo presentado en Circum-Pacific Conference, Session 8, Prehistoric TransPacific Contacts, Seattle, Washington. Recuperado en http://royalbcmuseum.bc.ca/ staffprofiles/ files/2013/09/LABRET-PAPER-1989-Grant-Keddie.pdf.

Kubicka, A. M., S. M. Rosin, P. Tryjanowski y E. Nelson

2017. A systematic review of animal predation creating pierced shells: implications for the archaeological record of the Old World. PeerJ 5:e2903

Kuhn, S.L.

2014. Signaling theory and technologies of communication in the paleolithic. Biological Theory 9: 42-50.

Kuhn, S. y M. Stiner

2007a. Body Ornamentation as Information Technology: Towards an Understanding of the Significance of Early Beads. Rethinking the Human Revolution: New Behavioral and Biological Perspectives on the Origins and Dispersal of Modern Humans (ed. por P. Mellars, K. Boyle, O. Bar-Yosef y C. Stringer), pp.45-54. MacDonald Institute Monographs, Cambridge.

2007b. Palaeolithic ornaments: implications for cognition, demography and identity. Diogenes 214:40-48.

Kuhn S. L., M.C. Stiner, D.S. Reese y E. Güleç

2001. Ornaments of the earliest Upper Paleolithic: 474 new insights from the Levant. Proceedings of the National Academy of Sciences of the 475 United States of America 98: 76417646.

Leonardt, $\mathrm{S}$.

2013. Artefactos malacológicos en el bosque y ecotono bosque - estepa del Noroeste de Patagonia. Tesis de Licenciatura, Facultad de Filosofía y Letras, Universidad de Buenos Aires, Buenos Aires.

2014. Producción local de cuentas de valva en el bosque del noroeste de Patagonia una aproximación desde la arqueología experimental Relaciones de la Sociedad Argentina de Antropología XXXIX (2): 463-482.

2017. Producción y distribución de cuentas de valva en el holoceno tardio de Patagonia continental argentina. Tesis de Doctorado, Facultad de Filosofía y Letras, Universidad de Buenos Aires, Buenos Aires. 
Loponte, D.

2008. Arqueología del Humedal del Paraná Inferior. Arqueología de la Cuenca del Plata, Serie Monográfica 1. Ediciones del Riel, Buenos Aires.

Loponte, D. y A. Acosta

2013. La construcción de la unidad arqueológica Guaraní en el extremo meridional de su distribución geográfica. Cuadernos Instituto Nacional de Antropología y Pensamiento Latinoamericano - Series Especiales 1(4): 193-235.

Loponte, D., A. Acosta y P. Tchilinguirian

2010. Avances en la arqueología de la Pampa Ondulada: sitios Hunter y Meguay. Arqueología Argentina en el Bicentenario de la Revolución de Mayo (ed. por J. R. Bárcena y H. Chiavazza), Tomo V, pp. 1811-1826. Universidad Nacional de Mendoza, Mendoza. 2016. Estructuras "monticulares", unidades arqueológicas y falsas premisas en la arqueología del noreste argentino. Anuario de Arqueología 8: 45-78.

Lothrop, S.

1932. Indians of the Paraná Delta River. Annals of the New York Academy of Sciences XXXIII. New York.

Madero, E.

1939. Historia del Puerto de Buenos Aires. Ediciones Buenos Aires, Buenos Aires.

Maeso Tognochi, C.

1977. Investigaciones Arqueológicas. Imprenta Don Bosco, Montevideo.

Martínez Soler, B. J.

1958-1959 Conchyliologia ethnologica. El uso ornamental y ceremonial de algunas especies de moluscos en territorio argentino. Runa 9 (1-2): 267-322.

Mazza, B. y D. Loponte. 2012. Las prácticas mortuorias en el humedal del Paraná inferior. Arqueología Iberoamericana 13: 3-21.

Mazza, B., A. Acosta, A.L. Guarido, N. Buc y D. Loponte

2018. Anthropogenic modifications to archaeological human bones from the lower Paraná River basin (Argentina). Journal of Archaeological Science: Reports 20: 647-661.

Moro Abadía, O. y A. Nowell

2015. Palaeolithic Personal Ornaments: Historical Development and Epistemological Challenges. Journal of Archaeological Method and Theory 22 (3): 952-979.

Müller, P.F.

1989. Etnografía de los Guaraní del Alto Paraná. CAEA Editorial, Rosario. 
Oliva, F. y M. L. Lisboa

2006. Estudio de Cuentas del Área Ecotonal Húmedo-Seca Pampeana (Sistema de Ventania y su Llanura adyacente). Revista de la Escuela de Antropología 12: 135-148.

Outes, F.

1917. Primer hallazgo arqueológico en la Isla Martín García. Anales de la Sociedad Científica XXXII: 265-277.

1918. La cultura guaraní en la cuenca del Paraná inferior. Anales de la Sociedad Científica argentina LXXXV: 153-181.

Parisi, F.

2013. Los moluscos de agua dulce en la dieta humana prehistórica en el

Humedal del Paraná inferior. Tesis de Licenciatura, Facultad de Filosofía y Letras, Universidad de Buenos Aires, Buenos Aires.

Parisi, F. S. y J. Liotta

2010. Primera aproximación al consumo de moluscos bivalvos (Diplodon sp.) en el sitio Cerro Lutz, planicies inundables del Paraná inferior. Mamül Mapu: pasado y presente desde la arqueología pampeana (ed. por M. Berón, L. Luna, M. Bonomo, C. Montalvo, C. Aranda y M. Carrera Aizpitarte), pp. 215-226. Editorial Libros del Espinillo, Ayacucho.

Pastor, S., I. Gordillo y L. Tissera. 2017. Objetos y paisajes multisensoriales del Holocenotardío inicial en el centro de Argentina (ca. 3900 añosAP). Acerca de un contexto arqueomalacológico de las Sierras de Córdoba. Intersecciones en Antropología 18: 317-327.

Pérez, $\mathrm{M}$.

2016. Tecnología de Producción y Uso de la Alfarería Durante el Holoceno Tardío en el Humedal del Paraná Inferior. PHD Disseration, Universidad de Buenos Aires. Ms.

Roach, M. E. y J. Eicher

1979. The Language of Personal Adornment. The Fabrics of Culture: The Anthropology of Clothing and Adornment (ed. por J. Cordwell y R. Schwarz), pp.7-21. Mouton Publishing, The Hague.

Rorabaugh, A. N. y K. A. Shantry

2016. From Labrets to Cranial Modification: Credibility Enhancing Displays and the Changing Expression of Coast Salish Resource Commitments. The Journal of Island and Coastal Archaeology 12 (3): 380-397.

Schaden, E.

1974. Aspectos fundamentais da cultura guaraní. Difusão Européia do Livro, São Paulo. 
Silvestre, $\mathrm{R}$.

2017. Tecnología Lítica en el Humedal del Paraná Inferior. PhD Disseration, Universidad de Buenos Aires. Ms.

Silvestre, R. y N. Buc.

2015. Experimentação e Traceologia: Explorando a funcionalidade dos "calibradores" dos sítios arqueológicos de tradição Tupiguarani, Argentina. Teoria E Sociedade 23 (1): 125-151.

Staden, $\mathrm{H}$.

1930 (1557). Viagem ao Brasil. Publicações da Academia Brasileir, Rio de Janeiro.

Stiner, M. C.

2014. Finding a Common Bandwidth: Causes of Convergence and Diversity in Paleolithic Beads. Biological Theory 9 (1): 51-64.

Suárez Diez, L.

([1975] 2002). Tipología de los objetos prehispánicos de concha. México, Instituto Nacional de Antropología e Historia

Szabó, K.

2005. Shell- working in the Western Pacific and Island Southeast Asia. PHD Dissertation, Australian National University, Canberre.

Sterelny, K. y P. Hiscock

2014. Symbols, Signals, and the Archaeological Record. Biological Theory 9 (1):1-3.

Torres, S., G. Darrigan y C. Damborenea

2013. Distribución del género Diplodon (Mollusca: Bivalvia: Hyriidae) en territorio Argentino mediante el uso de Colecciones Biológicas. Augmdomus (5): 90-99.

Torres, L. M.

1911. Los primitivos habitantes delta del Paraná. Biblioteca Centenaria Universidad de La Plata, La Plata.

Trubbit, M. B.

2003. The Production and Exchange of Marine Shell Prestige Goods. Journal of Archaeological Research 11 (3): 243-277.

Vanhaeren, M.

2005. Speaking with beads: The evolutionary significance of personal ornaments. From Tools to Symbols. From Early Hominids to Modern Humans (ed. por F. d'Errico y L. Blackwell), pp. 525-553. Witwatersrand University Press, Johannesburg. 
Vibe, I.

2007. San Personal Ornaments from the Later Stone Age at Blombos Cave and Blomboschfontein, Southern Cape, South Africa. Master Thesis, Department of Archaeology, University of Bergen, Bergen.

White, R.

1993. A social and technological view of Aurignacian and Castelperronian personal ornaments in France. El Origen del Hombre Moderno en el Suroeste de Europa (ed. por V. Cabrera Valdès), pp. 327-357. Ministerio de Educacion y Ciencia, Madrid 1999. Integrating social and operational complexity: the material construction of social identity at Sungir. L'Os: Festschrift for Henriette Camps-Fabrer, (ed. por A. Averbouh, P. Cattelain y M. Jullien), pp.120-37. Université de Marseille, Aix-en-Provence.

2007. Systems of Personal Ornamentation in the Early Upper Palaeolithic: Methodological Challenges and New Observations. Rethinking the Human Revolution: New Behavioral and Biological Perspectives on the Origin and Dispersal of Modern Human(ed. por P. Mellars, K. Boyle, O. Bar-Yoseff, y C. Stringer), pp. 287-302. McDonald Institute for Archaeological Research Cambridge, Cambridge.

Wiessner, P.

1984. Reconsidering the behavioral basis for style: a case study among the Kalahari San. Journal Anthropology Archaeology 3: 190-234.

Wobst, H. M. 1976. Stylistic Behavior and Information Exchange. Michigan Anthropological papers 61: 317-342.

Zilhão, J.

2007. The emergence of ornaments and art: an archaeological perspective on the origins of behavioural "modernity". Journal of Archaeological Research 15: 1-54.

Zubimendi, M. A.

2010. Malacological artifacts in Argentine Patagonia. Munibe. Suplemento: 262-270. 